\title{
Title: Decoding the risk of accepting online misinformation using Intelligence quotient and income
}

\author{
Author: Azad Kabir, MD MSPH; Raeed Kabir; Jebun Nahar, PhD; Ritesh Sengar;
}

Affiliations: Doctor Ai, LLC; 1120 Beach Blvd, Biloxi; MS 39530

Corresponding author's name and contact information (e-mail address, mailing address, phone number): Azad Kabir, MD, MSPH, ABIM; Doctor Ai, LLC; 1120 Beach Blvd, Biloxi; MS 39530; Email: azad.kabir@gmail.com; Cell: 228-342-6278

\begin{abstract}
:
The object of the study was to evaluate the risk factors associated with accepting online misinformation about COVID-19 vaccination in the United States. The percentages of fully vaccinated people, with regards to COVID-19, were considered as a surrogate measure of accepting online misinformation. The study evaluated the impact of the US state's average intelligence quotient (IQ) and per capita income on accepting misinformation. The study found that socio-demographic groups with lower income along with lower intelligence quotient (IQ) are more vulnerable to online misinformation theories surrounding COVID-19. Further study is needed to evaluate how to increase the intelligence quotient among low-income individuals and whether such an effort will reduce the acceptance of misinformation among the vulnerable population in the United States.
\end{abstract}

Title: Decoding the risk of accepting online misinformation using Intelligence quotient and income

\section{Introduction:}

Online misinformation surrounding COVID-19 vaccine is the major obstacle in fighting the coronavirus pandemic. Loomba et al. conducted randomized controlled trials in the UK and the USA, showing how exposure to online misinformation around COVID-19 vaccines affects intent to vaccinate to protect oneself or others. [1] The study found that some sociodemographic groups are differentially impacted by exposure to misinformation than others, and scientificsounding misinformation was found more strongly associated with declines in vaccination intent. Policy makers are struggling to stop online misinformation while COVID-19 pandemic is taking thousands of lives worldwide. Though a prior study found that certain socio-demographic groups are more vulnerable to online misinformation, no prior study looked at intelligence quotient (IQ) and per capita income as risk factors for accepting online misinformation. 


\section{Method:}

The US State's percentage of population fully vaccinated was considered as a surrogate's measure for accepting online misinformation among the mass population in any US states. The US vaccination data were obtained from NPR website as of $15^{\text {th }}$ of July 2021 [2]. The State level per capita income for the year 2010 to 2014 was collected from the U.S. Census Bureau data [3], and US State's average IQ scores were obtained from the McDaniel study published in 2006 [4]. McDaniel estimated State IQ from the National Assessment of Educational Progress (NAEP) standardized tests for reading and math (administered to a sample of public school children in each of the 50 states). The means of the standardized reading scores for grades 4 and 8 were averaged across years as well as the means of the standardized math scores for all 50 US states. Thus, State IQ used in this study was estimated using the average of mean reading and mean math scores [4].

All these four data sets were merged using Python data analysis software. In addition, all these variables were ranked in order to reduce measurement errors and reduce variability. The US States were ranked 1 to 50 based on the average intelligence quotient (IQ), where rank number 1 was the highest intelligence quotient (IQ) and 50 being the lowest. The US vaccination data were ranked from 1 to 50 where rank number 1 was the highest fully vaccinated state and 50th being the lowest. The State level per capita income was ranked from 1 to 50 as well where rank number 1 was the highest per capita income and 50 being the lowest. The correlation matrix, univariate analysis, and multivariate analysis were conducted using the Stata data analysis software.

\section{Results:}

The total of 50 US states were considered in the data analysis. The average US full vaccination rate was $47.5 \%( \pm 8.5)$ by July 15 th, 2021$)$, the average US population IQ was $100( \pm 2.71)$, and average per capita income was $\$ 28,889$. The most striking correlation coefficient was between income rank and fully vaccination rank, which was $0.67(p<0.001)$ shown in Table 1 . The correlation between average intelligence quotient (IQ) and vaccination rank was $0.44(<0.002)$. There was a strong correlation between average intelligence quotient (IQ) and income rank which was $0.36(<0.005)$, which indicates increasing income is directly correlated with increased intelligence quotient (IQ). Analysis was shown for rank for each variable as well as original values to show the effect of reduced variability while using the rank.

Table 1 shows state's per capita income and income rank are strongly correlated with percent fully vaccinated with correlation coefficients 0.69 and -0.71 , respectively. This indicates, average income has a parallel relationship to vaccination rates which means vaccination rate increases with increase of income. Again, the intelligence quotient rank and average intelligence quotient were also significantly correlated with percent fully vaccinated with correlation coefficients of 0.45 and -0.47 , respectively. This indicates, the intelligence quotient has a parallel relationship 
with vaccination rates which means vaccination increases with the increase of intelligence quotient.

Table 1: Correlation matrix of the variables used in the analysis: Demonstrating effect of population average intelligence quotient (IQ) and per capita income on percent fully vaccinated

\begin{tabular}{|c|c|c|c|c|c|c|}
\hline & $\begin{array}{c}\text { Vaccination } \\
\text { Rank }\end{array}$ & $\begin{array}{c}\text { \% Fully } \\
\text { Vaccinated }\end{array}$ & $\begin{array}{c}\text { IQ } \\
\text { Rank }\end{array}$ & $\begin{array}{c}\text { Average } \\
\text { IQ }\end{array}$ & $\begin{array}{l}\text { Income } \\
\text { Rank }\end{array}$ & $\begin{array}{l}\text { Per capita } \\
\text { Income }\end{array}$ \\
\hline Vaccination Rank & 1 & & & & & \\
\hline \multirow[t]{2}{*}{ \% Fully Vaccinated } & -0.99 & 1 & & & & \\
\hline & $<0.001$ & & & & & \\
\hline \multirow[t]{2}{*}{ IQ Rank } & 0.45 & -0.47 & 1 & & & \\
\hline & $<0.001$ & $<0.001$ & & & & \\
\hline \multirow[t]{2}{*}{ Average IQ } & -0.44 & 0.45 & -0.98 & 1 & & \\
\hline & $<0.002$ & $<0.001$ & $<0.001$ & & & \\
\hline \multirow[t]{2}{*}{ Income Rank } & -0.72 & -0.71 & 0.56 & -0.55 & 1 & \\
\hline & $<0.001$ & $<0.001$ & $<0.001$ & $<0.001$ & & \\
\hline \multirow[t]{2}{*}{ Per Capita Income } & -0.71 & 0.69 & -0.52 & 0.52 & -0.97 & 1 \\
\hline & $<0.001$ & $<0.001$ & $<0.001$ & $<0.001$ & $<0.001$ & \\
\hline
\end{tabular}

Figure 1 demonstrates there is a decreasing trend of states' populations who are fully vaccinated among populations with lower intelligence quotients (IQ). Given vaccination rate is used as a surrogate measure for assessing online misinformation, the findings indicate a parallel relationship with online misinformation (about vaccination) and low intelligence quotient (IQ). This has an $\mathrm{R}$ square value of $22.48 \%$ which means $22.48 \%$ variability of the vaccination is explained by the population intelligence quotient. 
Fig 1: Scatter plot of percentage of the US states total population fully vaccinated by state rank of IQ scores

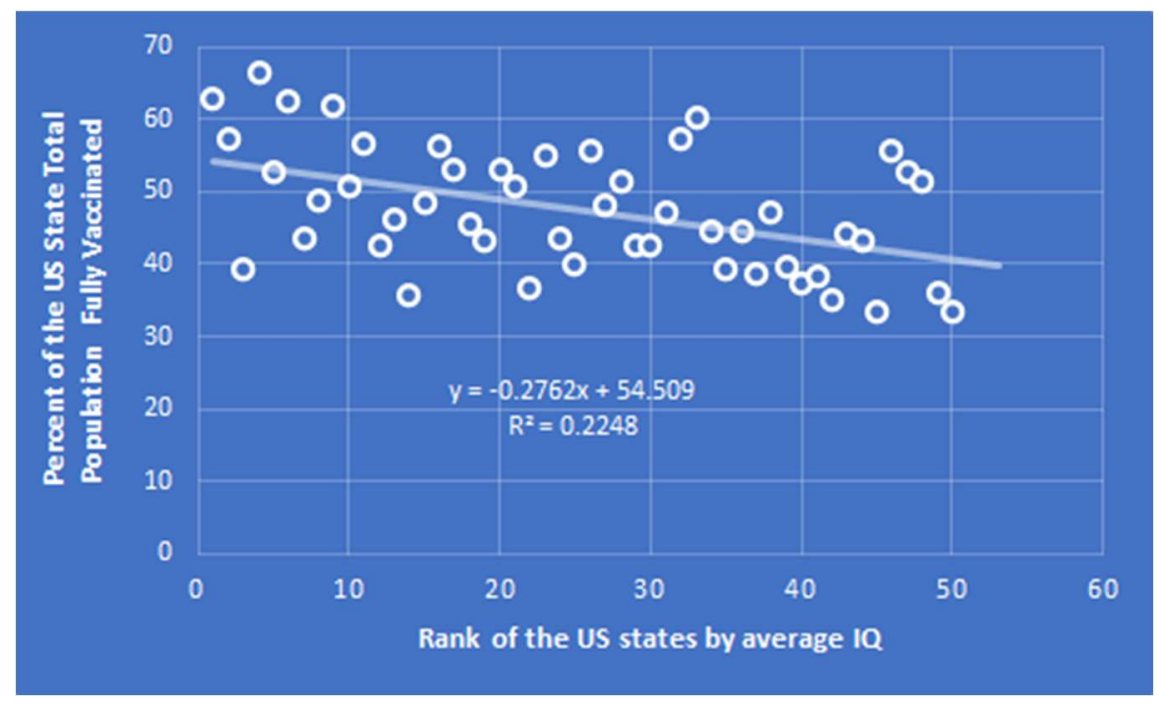

Figure 2 demonstrates there is a decreasing trend of population vaccination rates among the US states among lower income populations. As vaccination rate is used as a surrogate measure for accepting online misinformation, the findings indicate there is a parallel relationship between online misinformation (about vaccination) and low income populations. This has an $\mathrm{R}$ square value of $49.92 \%$ which means $49.92 \%$ variability of the vaccination is explained by income.

Fig 2: Scatter plot of percentage of the US states total population fully vaccinated by state's rank of per capita income.

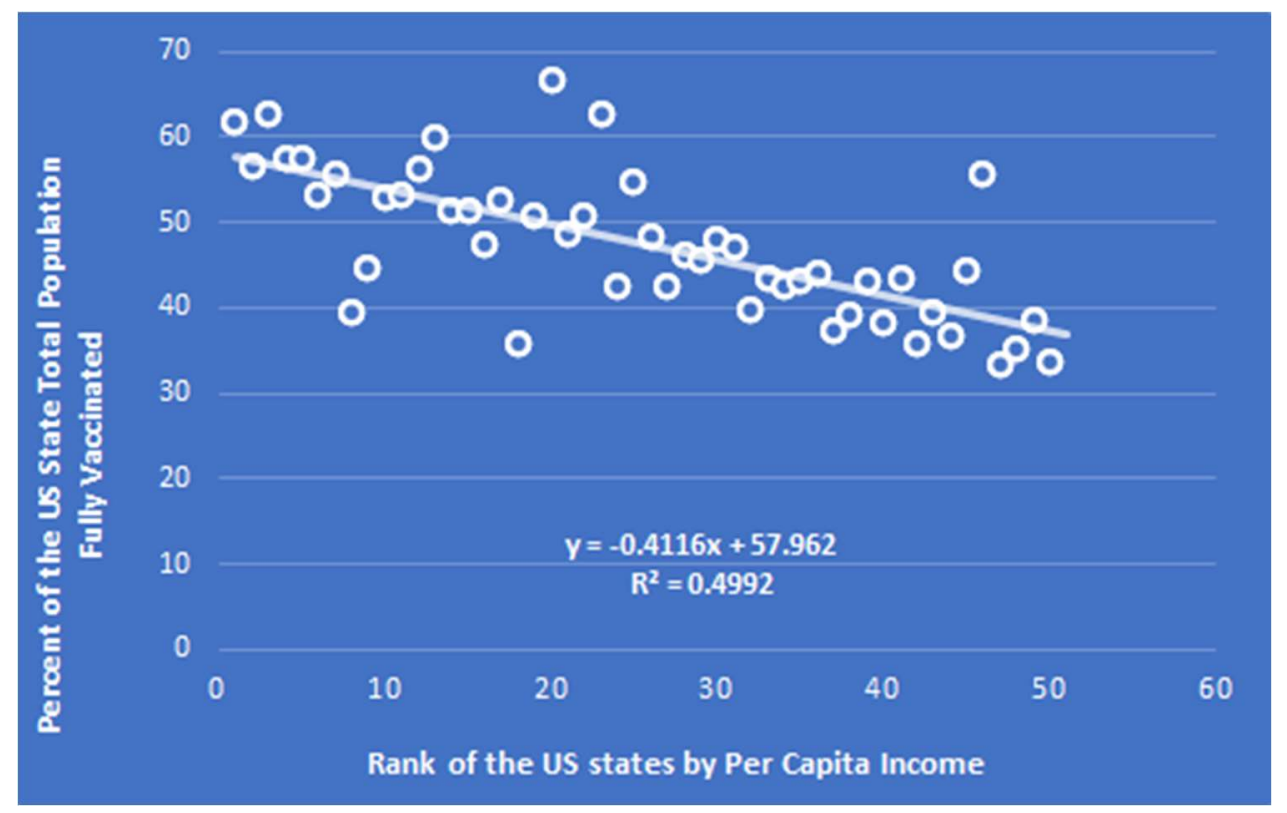

Figure 3 demonstrates there is a decreasing trend of per capita income among populations with lower intelligence quotients (IQ). Previous studies also reported national wealth strongly 
correlates with its population average IQ scores [5]. According to the current study, the population intelligence quotient explains $28.1 \%$ of the variability of the population income.

Fig 3: Scatter plot the US states per capita income by state rank of IQ scores

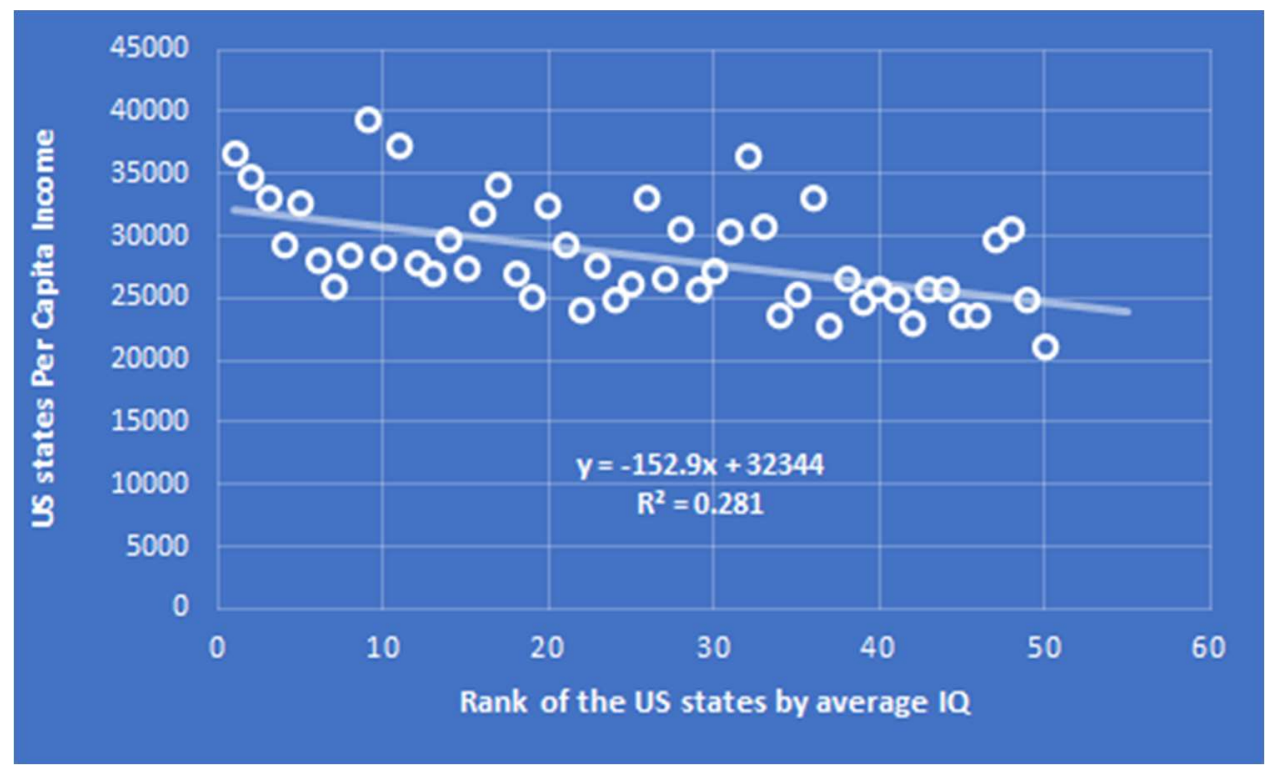

A multivariate analysis of state's percent vaccination was conducted using average intelligence quotient and per capita income as predictor variables (Table 2). The final model included only the interaction effect of the average intelligence quotient (IQ) and per capita income. When the independent effect of average intelligence quotient (IQ) and per capita income was entered in the model, all variables were non-significant. Hence, we removed the independent effect of average intelligence quotient (IQ) and per capita income from the model and the interaction effect was found strongly significant. The $\mathrm{R}$ square for the final model was 0.49 indicating only $49 \%$ variability of vaccination was explained by these two predictors. The final model also indicates populations vulnerable to online misinformation are lower income social-demographic groups who also have lower intelligence quotients. 
Table 2: Regression analysis demonstrating the interaction effect of average intelligence quotient and per capita income on percent fully vaccinated ( $R$ square $\mathbf{0 . 4 9}$ ).

\begin{tabular}{|c|c|c|c|c|c|}
\hline Variables & Coefficient & $\begin{array}{c}\text { Standard } \\
\text { Error }\end{array}$ & $\begin{array}{l}\text { Lower } \\
\text { Limit }\end{array}$ & Upper Limit & P-value \\
\hline $\begin{array}{l}\text { Product of } \\
\text { Average IQ and } \\
\text { Per capita Income }\end{array}$ & 1.27 & 0.19 & 0.89 & 1.65 & $<0.001$ \\
\hline Constant & 11.14 & 5.44 & 0.21 & 22.07 & $<0.046$ \\
\hline
\end{tabular}

Given this study found there is a significant interaction effect between the average intelligence quotient (IQ) and income while predicting percent fully vaccinated, quartiles of the intelligence quotient (IQ) and income were sorted by percent fully vaccinated in Table 3 . The study findings show there is a decreasing trend of vaccination by decreasing income quartiles $154.7 \%$ fully vaccinated among the highest quartiles and $39.9 \%$ vaccinated among the lowest quartiles of income). Similarly, there is a decreasing trend of vaccination by decreasing intelligence quotient quartiles (53.2\% fully vaccinated among the highest quartiles and $42.1 \%$ vaccinated among the lowest quartiles of average intelligence quotient). The analysis showed that the population with the lowest quartile per capita income and intelligence quotients are the least vaccinated, which was $38.8 \%( \pm 7.8)$. This finding indicates populations with lower income and lower intelligence quotient are the most vulnerable to online misinformation regarding COVID-19 vaccination. 
Table 3: Demonstrating interaction effect by sorting percents of full vaccination (accepting online misinformation) by quartiles of intelligence quotient and income

\begin{tabular}{|c|c|c|c|c|c|}
\hline Quartiles & $\begin{array}{l}\text { IQ Quartile } 1 \\
\text { >102.8 }\end{array}$ & $\begin{array}{c}\text { IQ Quartile } 2 \\
\text { (100.85 - 102.8) }\end{array}$ & $\begin{array}{l}\text { IQ Quartile } 3 \\
(102.8-98.6)\end{array}$ & $\begin{array}{l}\text { IQ Quartile } 4 \\
\text { (<98.6) }\end{array}$ & Total \\
\hline $\begin{array}{l}\text { Income Quartile } 1 \\
\qquad(>\$ 30,830)\end{array}$ & $\begin{array}{c}55.2 \%( \pm 8.5) \\
n=6\end{array}$ & $\begin{array}{c}54.2 \%( \pm 1.8) \\
n=3\end{array}$ & $\begin{array}{c}54.5 \%( \pm 6.8) \\
n=4\end{array}$ & $n=0$ & $\begin{array}{c}54.7 \%( \pm 6.5) \\
n=13\end{array}$ \\
\hline $\begin{array}{l}\text { Income Quartile } 2 \\
(\$ 27,546-\$ 30,830)\end{array}$ & $\begin{array}{c}54.3 \%( \pm 10.0) \\
n=5\end{array}$ & $\begin{array}{c}47.2 \%( \pm 10.1) \\
n=3\end{array}$ & $\begin{array}{c}49.3 \%( \pm 2.8) \\
n=2\end{array}$ & $\begin{array}{c}52 \%( \pm 1.0) \\
n=2\end{array}$ & $\begin{array}{c}51.3 \%( \pm 8.1) \\
n=12\end{array}$ \\
\hline $\begin{array}{l}\text { Income Quartile } 3 \\
(\$ 25,229-\$ 27,546)\end{array}$ & $\begin{array}{c}44.9 \%( \pm 1.8) \\
n=2\end{array}$ & $\begin{array}{c}44.7 \%( \pm 4.4) \\
n=3\end{array}$ & $\begin{array}{c}43.1 \%( \pm 3.6) \\
n=4\end{array}$ & $\begin{array}{c}43.0 \%( \pm 4.1) \\
n=4\end{array}$ & $\begin{array}{c}43.7 \%( \pm 3.4) \\
n=13\end{array}$ \\
\hline $\begin{array}{l}\text { Income Quartile } 4 \\
\qquad<\$ 25,229)\end{array}$ & $n=0$ & $\begin{array}{c}41.2 \%( \pm 3.8) \\
n=3\end{array}$ & $\begin{array}{c}41.6 \%( \pm 4.1) \\
n=2\end{array}$ & $\begin{array}{c}38.8 \%( \pm 7.8) \\
n=7\end{array}$ & $\begin{array}{c}39.9 \%( \pm 6.3) \\
n=12\end{array}$ \\
\hline Total & $\begin{array}{c}53.2 \%( \pm 8.8) \\
n=13\end{array}$ & $\begin{array}{c}46.8 \%( \pm 7.1) \\
n=12\end{array}$ & $\begin{array}{c}47.7 \%( \pm 7.1) \\
n=12\end{array}$ & $\begin{array}{c}42.1 \%( \pm 7.6) \\
n=13\end{array}$ & $\begin{array}{c}47.5 \%( \pm 8.5) \\
n=50\end{array}$ \\
\hline
\end{tabular}

\section{Discussion:}

Online misinformation surrounding the COVID-19 vaccination became a national security threat in the United States. The study findings indicate online misinformation heavily affects the population with lowest income and lowest intelligence quotient of the socio-demographic group. The study also found that income explains almost $50 \%$ of the vaccination variability with populations with lower income trends to be less vaccinated. In addition, the study also found populations with lower intelligence quotient are less likely to be vaccinated compared to those with high intelligence quotient and intelligence quotient explain $23 \%$ of the vaccination variability. 
The current study demonstrated a strong interaction effect of income and intelligence quotient which indicates populations with lowest income quartiles are most affected with online misinformation (about COVID-19) if they have lowest intelligence quotient. The study also found the population with highest income quartiles does not get affected by online misinformation even when those have lower intelligence quotient. This is a unique interaction effect and no other study reported similar findings in the past.

It is possible that even if certain individuals within the same state have high intelligence quotient (IQ), they may be vulnerable to misinformation as traditionally such misinformation propagates through their friends, families and acquaintances in the society. Roozenbeek et al. reported that higher trust in scientists and higher numeracy skills (which is the ability to use, interpret and communicate mathematical data, may be equivalent to intelligence quotient) were associated with lower susceptibility to COVID-19 related misinformation. The study demonstrated a clear link between susceptibility to misinformation and vaccine hesitancy and suggests interventions aiming to improve critical thinking and trust in science may be a promising avenue for future research [6]. It is possible that the socio-demographic group with lower intelligence quotient and income fails to interpret scientific data themself and depends on their trusted news source to understand scientific or mathematical data. This may lead to acceptance of online misinformation leading to lower vaccinations among the population with low income along with low intelligence quotient groups in the United States. .

The current study used state average data instead of individual data to find predictors of reduced vaccination which was used as a surrogate measure for accepting misinformation. It is possible that certain socio-demographic group or state population data reflects a more accurate picture than individual data given that misinformation needs a society or group-level enabler in order for the misinformation to propagate across the state.

Conclusion: Socio-demographic groups with lower income along with lower intelligence quotient are more vulnerable to online misinformation surrounding COVID-19. Further study is needed to evaluate how to increase the intelligence quotient among those with low income individuals and whether such effort will reduce acceptance of misinformation among the vulnerable population in the United States.

Conflict of Interest: The author has no conflict of interest to disclose.

\section{References:}

1. Loomba, S., de Figueiredo, A., Piatek, S.J. et al. Measuring the impact of COVID-19 vaccine misinformation on vaccination intent in the UK and USA. Nat Hum Behav 5, 337-348 (2021). https://doi.org/10.1038/s41562-021-01056-1

2. https://www.npr.org/sections/health-shots/2021/01/28/960901166/how-is-the-covid19-vaccination-campaign-going-in-your-state

3. "ACS DEMOGRAPHIC AND HOUSING ESTIMATES 2010-2014 American Community Survey 1-Year Estimates". U.S. Census Bureau. Archived from the original on 2020-02-14. Retrieved 2016-02-12. 
4. McDaniel, M. A. (2006). Estimating state IQ: Measurement challenges and preliminary correlates. Intelligence, 34(6), 607-619. doi:10.1016/j.intell.2006.08.007

5. Kabir, R.A.; Nahar, J.; Sengar, R.; Kabir, A.K. Wealth Code Unlocked: The Combined Effect of Emotional Intelligence and Intelligence Quotient. Preprints 2021, 2021070283 (doi: 10.20944/preprints202107.0283.v1).

6. Roozenbeek, J., Schneider, C. R., Dryhurst, S., Kerr, J., Freeman, A. L. J., Recchia, G., Van Der Bles, A. M., \& Van Der Linden, S. (2020). Susceptibility to misinformation about COVID-19 around the world: Susceptibility to COVID misinformation. Royal Society Open Science, 7(10). https://doi.org/10.1098/rsos.201199 